\title{
Outdoor air pollution and risk for kidney parenchyma cancer in 14 European cohorts
}

\section{Authors:}

Ole Raaschou-Nielsen, ${ }^{1,2 *}$ Marie Pedersen, ${ }^{1,3}$ Massimo Stafoggia, ${ }^{4,5}$ Gudrun Weinmayr, ${ }^{6}$ Zorana J Andersen, ${ }^{3}$ Claudia Galassi, ${ }^{7}$ Johan Sommar, ${ }^{8}$ Bertil Forsberg, ${ }^{8}$ David Olsson, ${ }^{8}$ Bente Oftedal, ${ }^{9}$ Norun H Krog, ${ }^{9}$ Gunn Marit Aasvang, ${ }^{9}$ Andrei Pyko, ${ }^{5}$ Göran Pershagen, ${ }^{5}$ Michal Korek, ${ }^{5}$ Ulf De Faire, ${ }^{5}$ Nancy L Pedersen, ${ }^{10}$ Claes-Göran Östenson, ${ }^{11}$ Laura Fratiglioni, ${ }^{12}$ Mette Sørensen, ${ }^{1}$ Kirsten T Eriksen, ${ }^{1}$ Anne Tjønneland, ${ }^{1}$ Petra H Peeters, ${ }^{13,14}$ Bas Bueno-de-Mesquita, ${ }^{14,15,16}$ Michelle Plusquin, ${ }^{14}$ Timothy J Key $^{17}$ Andrea Jaensch, ${ }^{6}$ Gabriele Nagel, ${ }^{6,18}$ Bernhard Föger, ${ }^{18}$ Meng Wang, ${ }^{19}$ Ming-Yi Tsai, ${ }^{19,20,30}$ Sara Grioni, ${ }^{21}$ Alessandro Marcon, ${ }^{22}$ Vittorio Krogh, ${ }^{21}$ Fulvio Ricceri, ${ }^{23,7}$ Carlotta Sacerdote, ${ }^{7}$ Enrica Migliore, ${ }^{7}$ Ibon Tamayo, ${ }^{24,25,26}$ Pilar Amiano, ${ }^{25,27}$ Miren Dorronsoro, ${ }^{25,27}$ Ranjeet Sokhi, ${ }^{28}$ Ingeborg Kooter, ${ }^{29}$ Kees de Hoogh, ${ }^{20,30}$ Rob Beelen, ${ }^{31,32}$ Marloes Eeftens, ${ }^{20,30}$ Roel Vermeulen, ${ }^{14,31,33}$ Paolo Vineis, ${ }^{14,34}$ Bert Brunekreef, ${ }^{31,33}$ and Gerard Hoek. ${ }^{31}$

\footnotetext{
Affiliations:

${ }^{1}$ The Danish Cancer Society Research Center, Copenhagen, Denmark

${ }^{2}$ Department of Environmental Science, Aarhus University, Roskilde, Denmark

${ }^{3}$ Centre for Epidemiology and Screening, Department of Public Health, University of Copenhagen, Copenhagen, Denmark

${ }^{4}$ Department of Epidemiology, Lazio Regional Health Service, Local Health Unit ASL RM1, Rome, Italy

${ }^{5}$ Institute of Environmental Medicine, Karolinska Institutet, Stockholm, Sweden

${ }^{6}$ Institute of Epidemiology and Medical Biometry, Ulm University, Ulm, Germany

${ }^{7}$ Unit of Cancer Epidemiology, Città della Salute e della Scienza University-Hospital and Center for Cancer Prevention (CPO), Turin, Italy

${ }^{8}$ Occupational and Environmental Medicine, Department of Public Health and Clinical Medicine, Umea University, Umea, Sweden

${ }^{9}$ Norwegian Institute of Public Health, Department of air pollution and noise, Oslo, Norway

${ }^{10}$ Department of Medical Epidemiology and Biostatistics, Karolinska Institute, Stockholm, Sweden

${ }^{11}$ Department of Molecular Medicine and Surgery, Karolinska Institute, Stockholm, Sweden

${ }^{12}$ Aging Research Center, Department of Neurobiology Care Science and Society, Karolinska Institute, Stockholm, Sweden

${ }^{13}$ Dept of Epidemiology, Julius Center for Health Sciences and Primary Care, University Medical Center Utrecht

${ }^{14}$ MRC-PHE Centre for Environment and Health, Department of Epidemiology and Biostatistics, School of Public Health, Imperial College, London, UK

${ }^{15}$ Department for Determinants of Chronic Diseases (DCD), National Institute for Public Health and the Environment (RIVM), Bilthoven, the Netherlands

${ }^{16}$ Department of Social \& Preventive Medicine, Faculty of Medicine, University of Malaya, Kuala Lumpur, Malaysia

${ }^{17}$ Cancer Epidemiology Unit, Nuffield Department of Population Health, University of Oxford, Oxford, The United Kingdom

${ }^{18}$ Agency for Preventive and Social Medicine, Bregenz, Austria

${ }^{19}$ Department of Environmental and Occupational Health Sciences, University of Washington, Seattle, WA, USA

${ }^{20}$ Swiss Tropical and Public Health Institute, Basel, Switzerland

${ }^{21}$ Epidemiology and Prevention Unit, Department of Preventive and Predictive Medicine, Fondazione IRCCS Istituto Nazionale dei
} 
Tumori, Milan, Italy

${ }^{22}$ Unit of Epidemiology \& Medical Statistics, Department of Diagnostics and Public Health, University of Verona, Verona, Italy

${ }^{23}$ Unit of Epidemiology, Regional Health Service ASL TO3, Grugliasco, Italy

${ }^{24}$ ISGlobal Institute de Salut Global Barcelona, Barcelona, Spain

${ }^{25}$ CIBER Epidemiología y Salud Pública (CIBERESP), Madrid, Spain

${ }^{26}$ Universitat Pompeu Fabra, Barcelona, Spain

${ }^{27}$ Public Health Department of Gipuzkoa, BioDonostia Research Institute, San Sebastian, Spain

${ }^{28}$ Centre for Atmospheric and Instrumentation Research, University of Hertfordshire, College Lane, Hatfield, The United Kingdom

${ }^{29}$ Netherlands Organization for Applied Scientific Research (TNO), Utrecht, The Netherlands

${ }^{30}$ University of Basel, Basel, Switzerland

${ }^{31}$ Institute for Risk Assessment Sciences, Utrecht University, Utrecht, The Netherlands

${ }^{32}$ National Institute for Public Health and the Environment (RIVM), Bilthoven, The Netherlands

${ }^{33}$ Julius Center for Health Sciences and Primary Care, University Medical Center Utrecht, Utrecht, The Netherlands;

${ }^{34}$ Molecular end Epidemiology Unit, HuGeF, Human Genetics Foundation, Torino, Italy

* Correspondence to: Ole Raaschou-Nielsen, Danish Cancer Society Research Center, Strandboulevarden 49, 2100 Copenhagen

Ø, Denmark. Email: ole@cancer.dk. Telephone: +453525 7617.

Running title: Air pollution and kidney parenchyma cancer

\section{What's new?}

Ambient air pollution is an established cause of lung cancer. It is of considerable public health interest whether air pollution also causes other cancers. A few studies indicated that air pollution might cause kidney cancer. These authors investigated a possible link between kidney parenchyma cancer and air pollution at the residence of 289,002 participants of 14 European cohorts. They found an increased risk in association with particulate matter air pollution, although not statistically significant.

\section{Conflicts of interest}

Bente Oftedal declares to own shares in three Norwegian companies: Statoil (oil and gas), Telenor (telecom) and Hafslund ASA (energy). However, she is not aware that this ownership has affected her scientific work or judgement. 


\section{Abstract}

Several studies have indicated weakly increased risk for kidney cancer among occupational groups exposed to gasoline vapors, engine exhaust, polycyclic aromatic hydrocarbons and other air pollutants, although not consistently. It was the aim to investigate possible associations between outdoor air pollution at the residence and the incidence of kidney parenchyma cancer in the general population. We used data from 14 European cohorts from the ESCAPE study. We geocoded and assessed air pollution concentrations at baseline addresses by land-use regression models for particulate matter $\left(\mathrm{PM}_{10}, \mathrm{PM}_{2.5}\right.$, $\mathrm{PM}_{\text {coarse }}, \mathrm{PM}_{2.5}$ absorbance (soot)) and nitrogen oxides $\left(\mathrm{NO}_{2}, \mathrm{NO}_{\mathrm{x}}\right)$, and collected data on traffic. We used Cox regression models with adjustment for potential confounders for cohort-specific analyses and random effects models for meta-analyses to calculate summary hazard ratios (HRs). The 289,002 cohort members contributed 4,111,908 person-years at risk. During follow-up (mean 14.2 years) 697 incident cancers of the kidney parenchyma were diagnosed. The meta-analyses showed higher HRs in association with higher PM concentration, e.g. $\mathrm{HR}=1.57$ (95\%CI: 0.81-3.01) per $5 \mu \mathrm{g} / \mathrm{m}^{3} \mathrm{PM}_{2.5}$ and $\mathrm{HR}=1.36(95 \% \mathrm{CI}: 0.84-2.19)$ per $10^{-5} \mathrm{~m}^{-1} \mathrm{PM}_{2.5}$ absorbance, albeit never statistically significant. The HRs in association with nitrogen oxides and traffic density on the nearest street were slightly above one. Sensitivity analyses among participants who did not change residence during follow-up showed stronger associations, but none were statistically significant. This study provides suggestive evidence that exposure to outdoor PM at the residence may be associated with higher risk for kidney parenchyma cancer; the results should be interpreted cautiously as associations may be due to chance. 


\section{INTRODUCTION}

A working group established under the International Agency for Research on Cancer recently classified outdoor air pollution in general, and particulate matter (PM) in particular, as carcinogenic to humans ${ }^{1}$. This classification was based on, among others, an extensive review of the epidemiological literature, which provided convincing evidence for an association with lung cancer. Positive associations were also noted for cancer of the urinary bladder and childhood leukaemia, whereas associations between air pollution and other cancers had only been sparsely studied ${ }^{1}$.

Over $90 \%$ of kidney cancers develop in the kidney parenchyma and the vast majority of these are adenocarcinomas (often denoted as renal cell carcinomas); the less than $10 \%$ of kidney cancers, which develops in the renal pelvis, are primarily of the transitional cell type ${ }^{2}$. Worldwide, the incidence rates of kidney cancer increased until the mid-1990s when they plateaued or declined in many countries ${ }^{2}$. Incidence rates of kidney parenchyma cancer are relatively high in Europe with rates between 3 and 15 per 100,000 in different countries ${ }^{2}$. Active tobacco smoking, obesity and hypertension are established risk factors for cancer of the kidney parenchyma ${ }^{2,3}$ and there is also suggestive evidence for, among others, exposure to environmental tobacco smoke ${ }^{4,5}$. Several studies of occupational groups, such as transport workers, drivers, policemen, metal foundry workers, and gasoline service station workers exposed to gasoline vapors, engine exhaust, polycyclic aromatic hydrocarbons, and other air pollutants, have indicated weakly increased risk for kidney cancer ${ }^{6-8}$, although the literature is neither consistent ${ }^{9}$ nor conclusive ${ }^{10}$. Garcia-Perez et al. found higher kidney cancer mortality in Spanish general populations exposed to ambient air pollution from incinerators and hazardous waste treatment plants ${ }^{11}$ and a cohort study of a general Danish population found positive but statistically insignificant 
associations between nitrogen oxides $\left(\mathrm{NO}_{\mathrm{x}}\right)$ at the residence and kidney cancer incidence but no association with amount of street traffic near the residence ${ }^{12}$. Further, ultrafine particles can translocate from the airways to the kidney and other organs of experimental animals ${ }^{13}$ and experiments have shown that diesel particles can induce cancer-relevant processes in the kidneys ${ }^{14,15}$.

We recently reported from the European Study of Cohorts for Air Pollution Effects (ESCAPE) that PM in outdoor air with a diameter $<10 \mu \mathrm{m}\left(\mathrm{PM}_{10}\right)$ and $2.5 \mu \mathrm{m}\left(\mathrm{PM}_{2.5}\right)$ at the residence is associated with risk for the development of lung cancer ${ }^{16}$ and natural-cause mortality ${ }^{17}$.

The aim of the present study was to investigate a possible association between outdoor air pollution and the risk for cancer of the kidney parenchyma in general European populations, applying the methods developed in ESCAPE. 


\section{MATERIALS AND METHODS}

\section{Design and participants}

The full ESCAPE study included 12 European areas where air pollution measurements were performed, land use regression (LUR) models were developed, and adult cohort studies with cancer incidence data were located. The present study included the 14 cohorts, located in 10 areas, with information on incident cancer, the most important potential confounders, with at least 20 incident kidney parenchyma cancer cases during follow-up and where the resources needed for participation were available. The 14 cohorts were in Sweden (European Prospective Investigation into Cancer and Nutrition[EPIC]-Umeå, Swedish National Study on Aging and Care in Kungsholmen [SNAC-K], Stockholm Screening Across the Lifespan Twin Study and TwinGene [SALT], Stockholm 60 years old and IMPROVE study [60-y/IMPROVE], Stockholm Diabetes Prevention Program [SDPP]), Norway (Oslo Health Study [HUBRO]), Denmark (Diet, Cancer and Health Study [DCH]), the Netherlands (EPIC-Monitoring Project on Risk Factors and Chronic Diseases in the Netherlands [MORGEN], EPIC-PROSPECT), the United Kingdom (EPIC-Oxford), Austria (Vorarlberg Health Monitoring and Prevention Programme [VHM\&PP]), Italy (EPIC-Varese, EPIC-Turin) and Spain (EPIC-San Sebastian); Figure 1). Our previous study on lung cancer included 312,944 participants of 17 cohorts in 12 study areas. The present study on kidney parenchyma cancer included 289,002 participants, i.e. a large fraction of our previous study. Most of the study areas were large cities and the surrounding suburban or rural communities, as specified in the online appendix (pp. 4-13). A pooled analysis of all cohort data was not possible due to data-transfer and privacy issues but data from the four Stockholm cohorts (SNAC-K, SALT, 60-y/IMPROVE and SDPP) were pooled, and analysed and denoted as one cohort (Cardiovascular Effects of Air pollution and Noise in Stockholm [CEANS]) in the following. 
Similarly, data from the two cohorts from the Netherlands (EPIC-MORGEN and EPIC-PROSPECT) were pooled, analysed and denoted as one [EPIC-NL]. Thus, ten cohort data sets were analysed. Information on lifestyle etc. among cohort participants was obtained by questionnaires or interviews at enrolment (see online appendix, Table S1). The local ethical and data protection authorities approved the use of cohort data. All participants signed informed consent forms at enrolment.

\section{Definition of incident cancer of the kidney parenchyma}

We included cancers located in the kidney parenchyma (ICD10/ICDO3: C64). We only included primary cancers (i.e. not metastases). The cohort members were followed up for cancer incidence in national or local cancer registries.

\section{Exposure assessment}

Annual outdoor air pollution concentrations at the baseline residential addresses of study participants were estimated by LUR models in a three-step, standardized procedure that has been described elsewhere ${ }^{18,19}$. First, $\mathrm{PM}$ with an aerodynamic diameter $<10 \mu \mathrm{m}\left(\mathrm{PM}_{10}\right)$, $\mathrm{PM}$ with aerodynamic diameter $<2.5 \mu \mathrm{m}\left(\mathrm{PM}_{2.5}\right), \mathrm{PM}_{2.5}$ absorbance (a marker for black carbon and soot), nitrogen dioxide $\left(\mathrm{NO}_{2}\right)$, and nitrogen oxides $\left(\mathrm{NO}_{\mathrm{x}}\right)$ were measured three times during different seasons at locations for each cohort population for 1 year between October 2008 and April 2011. Coarse PM was calculated as the difference between $\mathrm{PM}_{10}$ and $\mathrm{PM}_{2.5 .}$. In the Umeå, Varese and San Sebastian areas only $\mathrm{NO}_{2}$ and $\mathrm{NO}_{\mathrm{x}}$ was measured. Results from the three measurements were averaged, adjusting for temporal trends using data from a background monitoring site with continuous data ${ }^{18,20}$. PM filters were weighed before and after each measurement centrally at IRAS, Utrecht University. Second, we collected information about potential predictor variables relating to nearby traffic intensity, population/household 
density and land use from Geographic Information Systems (GIS), and evaluated these to explain spatial variation of annual average concentrations using regression modelling ${ }^{18,19}$. In general, predictors for $\mathrm{PM}_{10}, \mathrm{PM}_{2.5}, \mathrm{NO}_{\mathrm{x}}$ and $\mathrm{NO}_{2}$ related to traffic/roads and population/building density. Variables related to industry, port and altitude were also predictors in some models. These LUR models were evaluated using Leave-One-Out-Cross-Validation, which successively leaves one site out of the data and refits the model with the remaining N-1 sites. The models generally explained a large fraction of measured spatial variation, the $r^{2}$ from leave-one-out cross-validation usually falling between 0.60 and $0.80^{16}$. Finally, we used the models to assess exposure at the baseline address of each cohort member. If values of predictor variables for the cohort addresses were outside the range of values for the monitoring sites, we truncated the values to the minimum or maximum values at the monitoring sites. We truncated to prevent unrealistic predictions (e.g. related to too small distance to roads in GIS) and because we did not want to extrapolate the derived model beyond the range, for which it was developed. Truncation has been shown to improve predictions at independent sites ${ }^{21}$. We also collected information on traffic intensity (vehicles/day) on the nearest street. As part of the TRANSPHORM project, we used similar methods to predict concentrations of eight elements in PM at participants' baseline addresses ${ }^{22,23}$; we describe these procedures in the online appendix (pp. 2).

\section{Statistical analyses}

The association between long-term exposure to air pollution and incidence of kidney parenchyma cancer was analysed in each cohort separately at the local centre by common standardized protocols for exposure assessment, outcome definition, confounder models and statistical analyses. Cohort-specific effect estimates were combined by meta-analysis at the Danish Cancer Society Research Center, Copenhagen, Denmark. 
We fitted Cox proportional hazards regression models for each cohort, with age as the underlying time scale and followed up participants from enrolment until the time of a kidney parenchyma cancer diagnosis or censoring. We excluded participants with a cancer (except non-melanoma skin cancer) before enrolment and censored at the time of death, a diagnosis of any other cancer (except nonmelanoma skin cancer), emigration, or end of follow-up, whichever came first. We censored participants with another cancer because cancer treatment and change of life style might change the subsequent risk for development of another cancer. Air pollution exposure was analysed as a linear variable in three a-priori specified confounder models. Model 1 included sex, calendar time (year of enrolment; linear) and age (time axis). Model 2 additionally adjusted for smoking status (never/former/current), smoking intensity (g tobacco/day), smoking duration (years), occupation/employment status (different definitions, see online appendix pp. 3-13), educational level (low, medium, high), body mass index (BMI) (linear, $\mathrm{kg} / \mathrm{m}^{2}$ ) and hypertension (yes/no) (all referring to baseline). Model 3 (the main model) further adjusted for area-level socio-economic status. Information on at least age, sex, calendar time, smoking status, smoking intensity, smoking duration and BMI was available in all cohorts. We provide further information on the available variables and their definition and distribution in each cohort in the online appendix (pp. 4-13 and Table S1). Potential confounders were based on previous literature on risk factors for kidney cancer and availability.

We undertook a number of sensitivity analyses for each cohort, all with confounder model 3. First, we repeated the analyses after restriction to participants who had lived at the baseline address throughout the follow-up period, thus reducing misclassification of long-term exposure to air pollution in this subpopulation. Secondly, we added an indicator of degree of urbanization. Thirdly, we tested the linear 
assumption in the relation between each air pollutant and kidney parenchyma cancer by replacing the linear term with a natural cubic spline with three equally spaced inner knots, and compared the model fit of the linear and the spline models by the likelihood-ratio test. Fourthly, we repeated the analyses using back-extrapolated $\mathrm{NO}_{2}$ and $\mathrm{NO}_{\mathrm{x}}$ exposure data, which is described further in the online appendix (pp. 2-3).

In the meta-analysis, we used random-effects models to summarize the results for cohorts ${ }^{24} . \mathrm{I}^{2}$ statistics $^{25}$ and $p$ values for the $\chi^{2}$ test from Cochran's Q were calculated to determine heterogeneity among cohort-specific effect estimates. We used a common STATA (www.stata.com) script for all analyses.

\section{RESULTS}

Fourteen cohorts in seven European countries contributed to this study. Altogether 289,002 cohort members contributed 4,111,908 person-years at risk and 697 incident kidney parenchyma cases were registered during follow-up (mean, 14.2 years). The number of participants and cases varied considerably, the Austrian cohorts contributing almost half the cases (Table 1). The cohort areas represented a wide range of exposures, with 3-11 times higher mean air pollution concentrations in some Southern than Northern areas (Table 1). The variation in exposure within study areas was substantial, as shown previously ${ }^{16}$. The mean age at enrolment varied from 43 to 57 years (Table 1).

The meta-analyses showed higher summary hazard ratios (HRs) in association with higher PM 
concentration, e.g. $\mathrm{HR}=1.57$ (95\% CI: 0.81-3.01) per $5 \mu \mathrm{g} / \mathrm{m}^{3} \mathrm{PM}_{2.5}$ and $\mathrm{HR}=1.36$ (95\% CI: 0.84-2.19) per $10^{-5} \mathrm{~m}^{-1} \mathrm{PM}_{2.5}$ absorbance (soot), albeit never statistically significant (Table 2). The HRs in association with nitrogen oxides and traffic were slightly above one. Adjustment did not affect the summary HRs much (Table 2). The summary HRs for $\mathrm{PM}_{10}$, PM coarse and $\mathrm{PM}_{2.5}$ were based on low to moderate heterogeneity between cohort-specific results; all $p$ values for heterogeneity were $\geq 0.10$ (Table 2). For the large VHM\&PP cohort, HRs in association with $\mathrm{PM}_{2.5}$ and $\mathrm{PM}_{2.5}$ absorbance were lower than one $\left(\mathrm{PM}_{2.5} \mathrm{HR}=0.73 ; 95 \% \mathrm{CI}: 0.47-1.14\right)$; all other cohorts showed increased risk in association with $\mathrm{PM}_{2.5}$ exposure (Figure 2 and online Figure S1). Analyses based on participants who did not change residence during follow-up showed stronger associations, but none was statistically significant (Table 3). These results were based on stronger heterogeneity, which were statistically significant for $\mathrm{PM}_{2.5}$ and $\mathrm{PM}_{10}(\mathrm{p} \leq 0.01)$ (Table 3).

The assumption of linearity was not violated (online Table S2). Adjustment for degree of urbanization did not affect the results much (online Table S3) and use of back-extrapolated $\mathrm{NO}_{2}$ and $\mathrm{NO}_{\mathrm{x}}$ data only affected the results marginally (online appendix pp. 2-3 and Table S4).

Explorative analyses of $8 \mathrm{PM}$ elements in two particle fractions $\left(\mathrm{PM}_{10}\right.$ and $\left.\mathrm{PM}_{2.5}\right)$ showed mostly elevated HRs. HRs were elevated in both particle fractions for $\mathrm{Cu}, \mathrm{Fe}, \mathrm{Zn}, \mathrm{V}$ and $\mathrm{Si}$. With the exception of an HR of 2.17 (95\% CI: 1.19-3.97) per $100 \mathrm{ng} / \mathrm{m}^{3}$ vanadium in $\mathrm{PM}_{10}$, none of the HRs were statistically significant (online Table S5). Restriction to cohort participants who lived at the same residence during follow-up provided mostly higher HRs for the PM elements (online Table S5). 


\section{DISCUSSION}

This study showed elevated summary HRs for kidney parenchyma cancer incidence in association with higher concentration of four different measures of PM air pollution, albeit never statistically significant. The HRs in association with nitrogen oxides and traffic were close to one. Sensitivity analyses among participants who did not change residence during follow-up showed stronger associations, but none was statistically significant.

Our study benefited from a large number of cohort participants from general populations with widely different levels of air pollution and complete follow-up. The strengths of our study also include the use of standardized methods for exposure assessment and data analyses across all cohorts. We adjusted the analyses for a number of potential confounders. In particular, all cohort-specific analyses were adjusted for the important smoking variables smoking status, smoking intensity and smoking duration, but the possibility of residual confounding cannot be excluded. We assessed a comprehensive set of pollutants at address-level and the individual exposure assessment was based on actual measurements made in the development of LUR models for the detection of within-area contrasts. Since pooling of data across all cohorts was not possible we could not take full advantage of the exposure contrasts across Europe.

In the present study, the HRs for kidney parenchyma cancer were actually larger than those reported in the ESCAPE study for lung cancer, which were $1.22(1.03,1.45), 1.18(0.96,1.46)$ and $1.12(0.88,1.42)$ for $\mathrm{PM}_{10}, \mathrm{PM}_{2.5}$ and $\mathrm{PM}_{2.5}$ absorbance ${ }^{16}$. The confidence intervals of the HRs for kidney parenchyma cancer were wider, however, which is likely due to the smaller number of cases (697 kidney parenchyma versus 2095 lung cancer cases); the person time under risk was virtually the same. A previous study found an increased HR for kidney cancer in association with $\mathrm{NO}_{\mathrm{x}}$ at the residence ${ }^{12}$, 
which was not found in the present study. Our finding of non-significantly elevated HRs could be affected by a combination of the number of cancer cases, misclassification of exposure, confounding and chance. Several factors may have contributed to misclassification of the exposure. Although our LUR models performed well, with leave-one-out-cross-validation $\mathrm{r}^{2}$ values typically between 0.6 and $0.8^{16}$, any model incorporates some degree of misclassification. Also, we used data on air pollution for 2008-2011 in developing our LUR models but applied them to baseline addresses mainly 10-15 years earlier. Recent research in Rome, the Netherlands and Vancouver has shown that the spatial distribution of air pollution is relatively stable over 10 -year periods ${ }^{26-28}$, a study showed high correlations between traffic intensities on Dutch streets over a 10 year period ${ }^{29}$ and spatial models for black smoke in the United Kingdom provided reasonable predictions even going back to the $1960 \mathrm{~s}^{30}$, indicating that more recent estimations reflect also historical exposure contrasts. In our study, exposure was assessed at the enrolment address; moving from that address during follow-up might lead to misclassification of the exposure relevant to later development of cancer. Our results show stronger associations between air pollution and the risk for kidney parenchyma cancer among people who lived at the same address throughout follow-up, which would be expected if air pollution truly causes kidney parenchyma cancer. Altogether, we would expect the exposure misclassification in our study to be nondifferential and consequently not to create artificial associations but rather to influence the HRs towards unity. The previously reported associations between air pollution and all-cause mortality ${ }^{17}$ and lung cancer ${ }^{16}$ using the same exposure assessment method as in the present study indicates that the method indeed detects effects of exposure contrasts.

The airways are the primary target organs for inhaled particles but evidence from experimental studies with animals shows that ultrafine particles can translocate to other organs, such as the liver, kidneys, 
heart and brain ${ }^{13,31-33}$. Although the amount of particles accumulating in secondary target organs, such as the kidney, is many times lower than the lung tissue dose, it may be relevant for carcinogenic processes ${ }^{34,35}$. Experimental evidence supports that diesel particles induce cancer-relevant processes in the kidneys: diesel exhaust particles induced oxidative stress in cultured human kidney cells ${ }^{14}$ and exacerbated renal oxidative stress, inflammation and DNA damage in mice ${ }^{15}$. We are aware of no previous studies on outdoor PM air pollution and kidney cancer in general populations.

The explorative analyses of 8 PM elements showed mostly non-significantly elevated HRs for copper, iron, zinc, vanadium and silicon for both particle fractions. The vanadium content of $\mathrm{PM}_{2.5}$ was significantly associated with risk for kidney parenchyma cancer, with substantially elevated HRs in both $\mathrm{PM}_{10}$ and $\mathrm{PM}_{2.5}$. This may point to a specific source of particles. However, we do not want to over-interpret the vanadium findings as one significant association is close to what would be expected by chance among the 16 tests undertaken for the PM element analyses, given our 5\% significance level. Each PM element can be considered as representing different air pollution sources with copper, iron and zinc being indicators mainly of non-tailpipe traffic emissions such as brake and tyre wear, sulphur mainly indicating long-range transport, nickel and vanadium indicating mixed oil-burning and industry, silicon crustal material and potassium biomass burning ${ }^{22,36-38}$.

The Austrian VHM\&PP cohort was the only cohort where $\mathrm{PM}_{2.5}$ and $\mathrm{PM}_{2.5}$ absorbance (soot) was not associated with higher risk for kidney parenchyma cancer (Figure 2 and online Supplementary Figure S1). This large cohort influenced the summary HRs substantially: without the VHM\&PP cohort, the summary HR was $1.95(1.21,3.14)$ for $\mathrm{PM}_{2.5}$. We cannot explain the opposite results with any bias or design issue related to specifically this cohort; chance might be the explanation. The latter 
interpretation is supported by the fact that in the lung cancer and all-cause mortality ESCAPE analyses, elevated HRs were found for this cohort, that did not affect the summary HRs ${ }^{16,17}$. A post-hoc explanation could be that the concentrations of vanadium were lowest in this cohort, while vanadium was associated with the highest HRs among the analyzed PM elements.

In conclusion, this study provides suggestive evidence that exposure to outdoor PM at the residence may be associated with higher risk for kidney parenchyma cancer. The result should be interpreted with caution and future studies are needed to confirm or reject this hypothesis. 


\section{ACKNOWLEDGEMENTS}

This work was supported by the European Community's Seventh Framework Programme (FP7/20072011) under grant agreement numbers 211250 and 243406. M Pedersen holds a fellowship awarded from the Danish Council for Independent Research (grant DFF-4004-00179). G Weinmayr and G Nagel hold a grant from the German Cancer Aid (DKH ref. 111010). M Plusquin is supported by a Marie Curie Intra European Fellowship within the 7th European Community Framework Programme. The funding sources were not involved in the study design, in collection, analyses or interpretation of data, writing the manuscript, or in decision to submit the manuscript for publication.

\section{SUPPLEMENTARY DATA}

Supplementary data are available online. 


\section{REFERENCES}

1. International Agency for Research on Cancer Monograph Working Group. Outdoor air pollution. Monographs on the evaluation of carcinogenic risks to humans. Lyon: IARC Press; 2015.

2. Chow WH, Dong LM, Devesa SS. Epidemiology and risk factors for kidney cancer. Nat Rev Urol 2010; 7: 245-57.

3. International Agency for Research on Cancer Monograph Working group. Tobacco Smoke and Involuntary Smoking. Monographs on the evaluation of carcinogenic risks to humans. Lyon: IARC press; 2004.

4. Hu J, Ugnat AM, Canadian Cancer Registries Epidemiology Research G. Active and passive smoking and risk of renal cell carcinoma in Canada. Eur J Cancer 2005; 41: 770-8.

5. Theis RP, Dolwick Grieb SM, Burr D, Siddiqui T, Asal NR. Smoking, environmental tobacco smoke, and risk of renal cell cancer: a population-based case-control study. BMC Cancer 2008; 8: 387. 6. Ji J, Granstrom C, Hemminki K. Occupational risk factors for kidney cancer: a cohort study in Sweden. World J Urol 2005; 23: 271-8.

7. Lynge E, Andersen A, Nilsson R, Barlow L, Pukkala E, Nordlinder R, Boffetta P, Grandjean P, Heikkila P, Horte LG, Jakobsson R, Lundberg I, et al. Risk of cancer and exposure to gasoline vapors. Am J Epidemiol 1997; 145: 449-58.

8. Soll-Johanning $\mathrm{H}$, Bach E, Olsen JH, Tuchsen F. Cancer incidence in urban bus drivers and tramway employees: a retrospective cohort study. Occup Environ Med 1998; 55: 594-8.

9. Guo J, Kauppinen T, Kyyronen P, Heikkila P, Lindbohm ML, Pukkala E. Risk of esophageal, ovarian, testicular, kidney and bladder cancers and leukemia among Finnish workers exposed to diesel or gasoline engine exhaust. Int J Cancer 2004; 111: 286-92.

10. Lipworth L, Tarone RE, McLaughlin JK. The epidemiology of renal cell carcinoma. J Urol 2006; 176: 2353-8.

11. Garcia-Perez J, Fernandez-Navarro P, Castello A, Lopez-Cima MF, Ramis R, Boldo E, LopezAbente $\mathrm{G}$. Cancer mortality in towns in the vicinity of incinerators and installations for the recovery or disposal of hazardous waste. Environ Int 2013; 51: 31-44.

12. Raaschou-Nielsen O, Andersen ZJ, Hvidberg M, Jensen SS, Ketzel M, Sorensen M, Hansen J, Loft S, Overvad K, Tjonneland A. Air pollution from traffic and cancer incidence: a Danish cohort study. Environ Health 2011; 10: 67.

13. Kreyling WG, Semmler-Behnke M, Seitz J, Scymczak W, Wenk A, Mayer P, Takenaka S, Oberdorster $\mathrm{G}$. Size dependence of the translocation of inhaled iridium and carbon nanoparticle aggregates from the lung of rats to the blood and secondary target organs. Inhal Toxicol 2009; 21 Suppl 1: 55-60.

14. Waly MI, Ali BH, Nemmar A. Acute effects of diesel exhaust particles and cisplatin on oxidative stress in cultured human kidney (HEK 293) cells, and the influence of curcumin thereon. Toxicology in vitro : an international journal published in association with BIBRA 2013; 27: 2299-304.

15. Nemmar A, Karaca T, Beegam S, Yuvaraju P, Yasin J, Hamadi NK, Ali BH. Prolonged Pulmonary Exposure to Diesel Exhaust Particles Exacerbates Renal Oxidative Stress, Inflammation and DNA Damage in Mice with Adenine-Induced Chronic Renal Failure. Cell Physiol Biochem 2016; 38: 1703-13. 
16. Raaschou-Nielsen O, Andersen ZJ, Beelen R, Samoli E, Stafoggia M, Weinmayr G, Hoffmann B, Fischer P, Nieuwenhuijsen MJ, Brunekreef B, Xun WW, Katsouyanni K, et al. Air pollution and lung cancer incidence in 17 European cohorts: prospective analyses from the European Study of Cohorts for Air Pollution Effects (ESCAPE). Lancet Oncol 2013; 14: 813-22.

17. Beelen R, Raaschou-Nielsen O, Stafoggia M, Andersen ZJ, Weinmayr G, Hoffmann B, Wolf K, Samoli E, Fischer P, Nieuwenhuijsen M, Vineis P, Xun WW, et al. Effects of long-term exposure to air pollution on natural-cause mortality: an analysis of 22 European cohorts within the multicentre ESCAPE project. Lancet 2014; 383: 785-95.

18. Eeftens M, Beelen R, de HK, Bellander T, Cesaroni G, Cirach M, Declercq C, Dedele A, Dons E, de NA, Dimakopoulou K, Eriksen K, et al. Development of Land Use Regression models for PM(2.5), $\mathrm{PM}(2.5)$ absorbance, $\mathrm{PM}(10)$ and $\mathrm{PM}$ (coarse) in 20 European study areas; results of the ESCAPE project. Environ Sci Technol 2012; 46: 11195-205.

19. Beelen R, Hoek G, Vienneau D, M E, Dimakopoulou K, Pedeli X, Tsai M-Y, Kunzli N, Schikowski $\mathrm{T}, \mathrm{A} \mathrm{M}$, al. e. Development of NO2 and NOx land use regression models for estimating air pollution exposure in 36 study areas in Europe - the ESCAPE project. Atmos Environ 2013; 72: 10-23.

20. Eeftens M, Tsai M-Y, Ampe C, Anwander B, Beelen R, Bellander T, Cesaroni G, Cirach M, Cyrys J, de Hoogh K, De Nazelle A, de Vocht F, et al. Spatial variation of PM2.5, PM10 and PM2.5 absorbance and $\mathrm{PM}$ coarse concentrations between and within 20 European study areas and the relationship with NO2 - results of the ESCAPE project. Atmos Environ 2012; 62: 303-17.

21. Wang M, Beelen R, Eeftens M, Meliefste K, Hoek G, Brunekreef B. Systematic evaluation of land use regression models for no2. Environ Sci Technol 2012; 46: 4481.

22. de Hoogh K, Wang M, Adam M, Badaloni C, Beelen R, Birk M, Cesaroni G, Cirach M, Declercq C, Dedele A, Dons E, de Nazelle A, et al. Development of land use regression models for particle composition in twenty study areas in Europe. Environ Sci Technol 2013; 47: 5778-86.

23. Raaschou-Nielsen O, Beelen R, Wang M, Hoek G, Andersen ZJ, Hoffmann B, Stafoggia M, Samoli E, Weinmayr G, Dimakopoulou K, Nieuwenhuijsen M, Xun WW, et al. Particulate matter air pollution components and risk for lung cancer. Environ Int 2016; 87: 66-73.

24. DerSimonian R, Laird N. Meta-analysis in clinical trials. Control Clin Trials 1986; 7: 177-88.

25. Higgins JP, Thompson SG. Quantifying heterogeneity in a meta-analysis. Stat Med 2002; 21 : 1539-58.

26. Cesaroni G, Porta D, Badaloni C, Stafoggia M, Eeftens M, Meliefste K, Forastiere F. Nitrogen dioxide levels estimated from land use regression models several years apart and association with mortality in a large cohort study. Environ Health 2012; 11: 48.

27. Eeftens M, Beelen R, Fischer P, Brunekreef B, Meliefste K, Hoek G. Stability of measured and modelled spatial contrasts in NO(2) over time. Occup Environ Med 2011; 68: 765-70.

28. Wang R, Henderson SB, Sbihi H, Allen RW, Brauer M. Temporal stability of land use regression models for traffic-related air pollution. Atmos Environ 2013; 64: 312-9.

29. Beelen R, Hoek G, Fischer P, van den Brandt PA, Brunekreef B. Estimated long-term outdoor air pollution concentrations in a cohort study. Atmospheric Environment 2007; 41: 1343-58.

30. Gulliver J, Morris C, Lee K, Vienneau D, Briggs D, Hansell A. Land use regression modeling to estimate historic (1962-1991) concentrations of black smoke and sulfur dioxide for Great Britain.

Environ Sci Technol 2011; 45: 3526-32. 
31. Oberdorster G, Sharp Z, Atudorei V, Elder A, Gelein R, Kreyling W, Cox C. Translocation of inhaled ultrafine particles to the brain. Inhal Toxicol 2004; 16: 437-45.

32. Elder A, Gelein R, Silva V, Feikert T, Opanashuk L, Carter J, Potter R, Maynard A, Ito Y, Finkelstein J, Oberdorster G. Translocation of inhaled ultrafine manganese oxide particles to the central nervous system. Environ Health Perspect 2006; 114: 1172-8.

33. Pery AR, Brochot C, Hoet PH, Nemmar A, Bois FY. Development of a physiologically based kinetic model for $99 \mathrm{~m}$-technetium-labelled carbon nanoparticles inhaled by humans. Inhal Toxicol 2009; 21: 1099-107.

34. Schmid O, Moller W, Semmler-Behnke M, Ferron GA, Karg E, Lipka J, Schulz H, Kreyling WG, Stoeger T. Dosimetry and toxicology of inhaled ultrafine particles. Biomarkers 2009; 14 Suppl 1: 67-73. 35. Peters A, Veronesi B, Calderon-Garciduenas L, Gehr P, Chen LC, Geiser M, Reed W, RothenRutishauser B, Schurch S, Schulz H. Translocation and potential neurological effects of fine and ultrafine particles a critical update. Part Fibre Toxicol 2006; 3: 13.

36. Eeftens M, Hoek G, Gruzieva O, Molter A, Agius R, Beelen R, Brunekreef B, Custovic A, Cyrys J, Fuertes $E$, Heinrich J, Hoffmann B, et al. Elemental composition of particulate matter and the association with lung function. Epidemiology 2014; 25: 648-57.

37. Viana M, Kuhlbusch TAJ, Querol X, Alastuey A, Harrison RM, Hopke PK, Winiwarter W, Vallius M, Szidat S, Prévôt ASH, Hueglin C, Bloemen $\mathrm{H}$, et al. Source apportionment of particulate matter in Europe: A review of methods and results. Journal of Aerosol Science 2008; 39: 827-49.

38. Wang M, Beelen R, Stafoggia M, Raaschou-Nielsen O, Andersen ZJ, Hoffmann B, Fischer P, Houthuijs D, Nieuwenhuijsen M, Weinmayr G, Vineis $P$, Xun WW, et al. Long-term exposure to elemental constituents of particulate matter and cardiovascular mortality in 19 European cohorts: results from the ESCAPE and TRANSPHORM projects. Environ Int 2014; 66: 97-106.

\section{FIGURE LEGENDS}

Figure 1. Areas where cohort members lived, measurements were taken and land-use regression models for prediction of air pollution were developed.

Figure 2. Cohort-specific associations between $\mathrm{PM}_{2.5}$ (upper Forest plot, HRs per $5 \mu \mathrm{g} / \mathrm{m}^{3}$ ), $\mathrm{NO}_{2}($ lower Forest plot, HRs per $10 \mu \mathrm{g} / \mathrm{m}^{3}$ ) and risk for kidney parenchyma cancer 
Table 1. Participants, kidney cancer cases, mean air pollution concentrations, and traffic in cohorts.

\begin{tabular}{|c|c|c|c|c|c|c|c|c|c|c|c|}
\hline Cohort, location & $\mathrm{N}_{\text {participants }}$ & $\begin{array}{c}\text { Mean age } \\
\text { at } \\
\text { baseline } \\
\text { (years) }\end{array}$ & $\begin{array}{l}\text { Person- } \\
\text { years at } \\
\text { risk }\end{array}$ & $\mathrm{N}_{\text {cases }}$ & $\begin{array}{c}\mathrm{PM}_{10} \\
\left(\mu \mathrm{g} / \mathrm{m}^{3}\right)\end{array}$ & $\begin{array}{l}\mathrm{PM}_{\text {coarse }} \\
\left(\mu \mathrm{g} / \mathrm{m}^{3}\right)\end{array}$ & $\begin{array}{c}\mathrm{PM}_{2.5} \\
\left(\mu \mathrm{g} / \mathrm{m}^{3}\right)\end{array}$ & $\begin{array}{l}\mathrm{PM}_{2.5} \mathrm{abs} \\
\left(10^{-5} \mathrm{~m}^{-1}\right)\end{array}$ & $\begin{array}{c}\mathrm{NO}_{2} \\
\left(\mu \mathrm{g} / \mathrm{m}^{3}\right)\end{array}$ & $\begin{array}{c}\mathrm{NO}_{\mathrm{x}} \\
\left(\mu \mathrm{g} / \mathrm{m}^{3}\right)\end{array}$ & $\begin{array}{c}\text { Traffic on nearest } \\
\text { street (vehicles/day) }\end{array}$ \\
\hline $\begin{array}{l}\text { EPIC-Umeå, } \\
\text { Umeå, Sweden }\end{array}$ & 21596 & 46 & 290220 & 30 & NA & NA & NA & NA & 5.2 & 8.7 & 845 \\
\hline $\begin{array}{l}\text { HUBRO, Oslo, } \\
\text { Norway }\end{array}$ & 17786 & 48 & 151559 & 21 & 13.5 & 4.0 & 8.9 & 1.2 & 20.9 & 38.2 & 2495 \\
\hline $\begin{array}{l}\text { CEANS, } \\
\text { Stockholm, } \\
\text { Sweden }\end{array}$ & 17161 & 56 & 179913 & 43 & 14.6 & 7.1 & 7.1 & 0.6 & 10.7 & 18.9 & 1531 \\
\hline $\begin{array}{l}\text { DCH, } \\
\text { Copenhagen, } \\
\text { Denmark }\end{array}$ & 37643 & 57 & 556466 & 125 & 17.2 & 5.7 & 11.3 & 1.2 & 16.4 & 26.8 & 3023 \\
\hline $\begin{array}{l}\text { EPIC-NL, the } \\
\text { Netherlands }\end{array}$ & 30120 & 50 & 355756 & 46 & 25.4 & 8.5 & 16.8 & 1.4 & 25.2 & 37.9 & 1292 \\
\hline $\begin{array}{l}\text { EPIC-Oxford, } \\
\text { London/Oxford, } \\
\text { United Kingdom }\end{array}$ & 35886 & 45 & 392233 & 22 & 16.0 & 6.4 & 9.8 & 1.1 & 24.4 & 40.8 & 1392 \\
\hline $\begin{array}{l}\text { VHM\&PP, } \\
\text { Voralberg, } \\
\text { Austria }\end{array}$ & 103347 & 43 & 1873157 & 324 & 20.6 & 6.7 & 13.6 & 1.7 & 19.9 & 39.9 & 1685 \\
\hline EPIC Varese & 10299 & 52 & 111092 & 29 & NA & NA & NA & NA & 43.5 & 86.7 & NA \\
\hline
\end{tabular}


Varese, Italy EPIC-Turin, Turin, Italy 7578 54 108716

22

46.5

16.5

30.1

3.1

53.2

96.4

4018

EPIC-San

Sebastian, San

Sebastian, Spain

7586

49

92796

35

NA

NA

NA

NA

23.8

47.2

NA

$\mathrm{PM}_{2.5}$ abs, $\mathrm{PM}_{2.5}$ absorption

NA, not available 
Table 2. Random-effects meta-analyses hazard ratios for kidney parenchyma cancer in association with exposure to six air pollutants and a traffic indicator and measures of heterogeneity between underlying cohort-specific results.

\begin{tabular}{|c|c|c|c|c|c|c|c|}
\hline \multirow{3}{*}{ Exposure } & \multirow{3}{*}{ Increase } & \multirow{3}{*}{$\begin{array}{l}\text { No. of } \\
\text { Cohorts }\end{array}$} & \multicolumn{3}{|c|}{ HR $(95 \% \mathrm{CI})$} & \multicolumn{2}{|c|}{$\begin{array}{c}\text { Measures of heterogeneity } \\
\text { between cohorts }\end{array}$} \\
\hline & & & Model $1^{2}$ & Model $2^{3}$ & Model $3^{4}$ & \multicolumn{2}{|c|}{ Model 3} \\
\hline & & & & & & $\mathrm{I}^{2}(\%)$ & $\mathrm{p}^{5}$ \\
\hline $\mathrm{PM}_{10}$ & $10 \mu \mathrm{g} / \mathrm{m}^{3}$ & 7 & $1.40(0.87-1.51)$ & $1.39(0.87-2.20)$ & $1.29(0.85-1.96)$ & 25 & 0.24 \\
\hline $\mathrm{PM}_{2.5}$ & $5 \mu \mathrm{g} / \mathrm{m}^{3}$ & 7 & $1.46(0.81-2.61)$ & $1.48(0.81-2.70)$ & $1.57(0.81-3.01)$ & 44 & 0.10 \\
\hline $\mathrm{PM}_{\text {coarse }}$ & $5 \mu \mathrm{g} / \mathrm{m}^{3}$ & 7 & $1.11(0.82-1.51)$ & $1.12(0.80-1.56)$ & $1.08(0.80-1.45)$ & 0 & 0.53 \\
\hline $\mathrm{PM}_{2.5}$ absorbance & $10^{-5} \mathrm{~m}^{-1}$ & 7 & $1.43(0.89-2.31)$ & $1.54(0.90-2.63)$ & $1.36(0.84-2.19)$ & 25 & 0.24 \\
\hline $\mathrm{NO}_{2}$ & $10 \mu \mathrm{g} / \mathrm{m}^{3}$ & 10 & $1.06(0.93-1.21)$ & $1.10(0.94-1.28)$ & $1.04(0.92-1.19)$ & 13 & 0.32 \\
\hline $\mathrm{NO}_{\mathrm{x}}$ & $20 \mu \mathrm{g} / \mathrm{m}^{3}$ & 10 & $1.03(0.93-1.14)$ & $1.04(0.94-1.15)$ & $1.03(0.93-1.14)$ & 0 & 0.69 \\
\hline $\begin{array}{l}\text { Traffic density on } \\
\text { nearest street }\end{array}$ & $\begin{array}{l}5000 \text { vehicles } \\
\text { per day }\end{array}$ & 8 & $1.03(0.95-1.11)$ & $1.02(0.95-1.10)$ & $1.02(0.95-1.10)$ & 0 & 0.87 \\
\hline
\end{tabular}

Within each cohort, we included only participants without missing data in any of the variables included in model 3, thus using an identical data set for analyses with all three models within the same cohort.

${ }^{1}$ The four Stockholm cohorts were pooled and only count one. Similarly, the two Dutch EPIC cohorts were pooled and only count one.

${ }^{2}$ Model 1: age (time scale in Cox model), sex, calendar time

${ }^{3}$ Model 2: Model $1+$ smoking status, smoking intensity, smoking duration, occupation/employment status, educational level, BMI, hypertension

${ }^{4}$ Model 3: Model $2+$ area-level socio-economic status

${ }^{5}$ Cochran test for heterogeneity 
Table 3. Random-effects meta-analyses hazard ratios for kidney parenchyma cancer in association with exposure to six air pollutants and a traffic indicator for all participants and for those with the same residence during the whole follow-up period (non-movers). All results derive from analyses with confounder model $3^{1}$.

\begin{tabular}{|c|c|c|c|c|c|c|}
\hline \multirow[b]{2}{*}{ Exposure } & \multirow[b]{2}{*}{ Increase } & \multicolumn{3}{|c|}{$\operatorname{HR}(95 \% \mathrm{CI})$} & \multirow{2}{*}{\multicolumn{2}{|c|}{$\begin{array}{c}\text { Measures of heterogeneity } \\
\text { between cohorts }\end{array}$}} \\
\hline & & $\begin{array}{l}\text { All cohorts; all } \\
\text { participants (repeated } \\
\text { for comparison) }\end{array}$ & $\begin{array}{l}\text { Cohorts with non- } \\
\text { mover information }{ }^{2} \text {; } \\
\text { all participants }\end{array}$ & $\begin{array}{l}\text { Cohorts with non- } \\
\text { mover information; } \\
\text { non-movers }\end{array}$ & & \\
\hline & & & & & $\mathrm{I}^{2}(\%)$ & p-value ${ }^{3}$ \\
\hline $\mathrm{PM}_{10}$ & $10 \mu \mathrm{g} / \mathrm{m}^{3}$ & $1.29(0.85-1.96)$ & $1.33(0.82-2.17)$ & $1.72(0.73-4.08)$ & 68 & 0.01 \\
\hline $\mathrm{PM}_{2.5}$ & $5 \mu \mathrm{g} / \mathrm{m}^{3}$ & $1.57(0.81-3.01)$ & $1.73(0.72-4.18)$ & $2.62(0.68-10.1)$ & 74 & 0.003 \\
\hline $\mathrm{PM}_{\text {coarse }}$ & $5 \mu \mathrm{g} / \mathrm{m}^{3}$ & $1.08(0.80-1.45)$ & $1.15(0.82-1.59)$ & $1.45(0.92-2.30)$ & 20 & 0.29 \\
\hline $\mathrm{PM}_{2.5}$ absorbance & $10^{-5} \mathrm{~m}^{-1}$ & $1.36(0.84-2.19)$ & $1.37(0.71-2.65)$ & $1.67(0.75-3.71)$ & 38 & 0.16 \\
\hline $\mathrm{NO}_{2}$ & $10 \mu \mathrm{g} / \mathrm{m}^{3}$ & $1.04(0.92-1.19)$ & $0.99(0.86-1.15)$ & $1.08(0.82-1.43)$ & 51 & 0.07 \\
\hline $\mathrm{NO}_{\mathrm{x}}$ & $20 \mu \mathrm{g} / \mathrm{m}^{3}$ & $1.03(0.93-1.14)$ & $1.00(0.90-1.12)$ & $1.04(0.81-1.34)$ & 51 & 0.07 \\
\hline $\begin{array}{l}\text { Traffic density on } \\
\text { nearest road }\end{array}$ & $\begin{array}{l}5000 \\
\text { vehicles } \\
\text { per day }\end{array}$ & $1.02(0.95-1.10)$ & $1.03(0.95-1.11)$ & $1.04(0.94-1.16)$ & 0 & 0.74 \\
\hline
\end{tabular}

${ }^{1}$ Model 3: age (time scale in Cox model), sex, calendar time, smoking status, smoking intensity, smoking duration, occupation/employment status, educational level, BMI, hypertension, area-level socio-economic status

${ }^{2}$ EPIC-Umeå, EPIC-Netherlands, EPIC-Turin and EPIC-San Sebastian had no information on changes of residence during follow-up.

${ }^{3}$ Cochran test for heterogeneity 
Figure 1. Areas where cohort members lived, measurements were taken and land-use regression models for prediction of air pollution were developed.

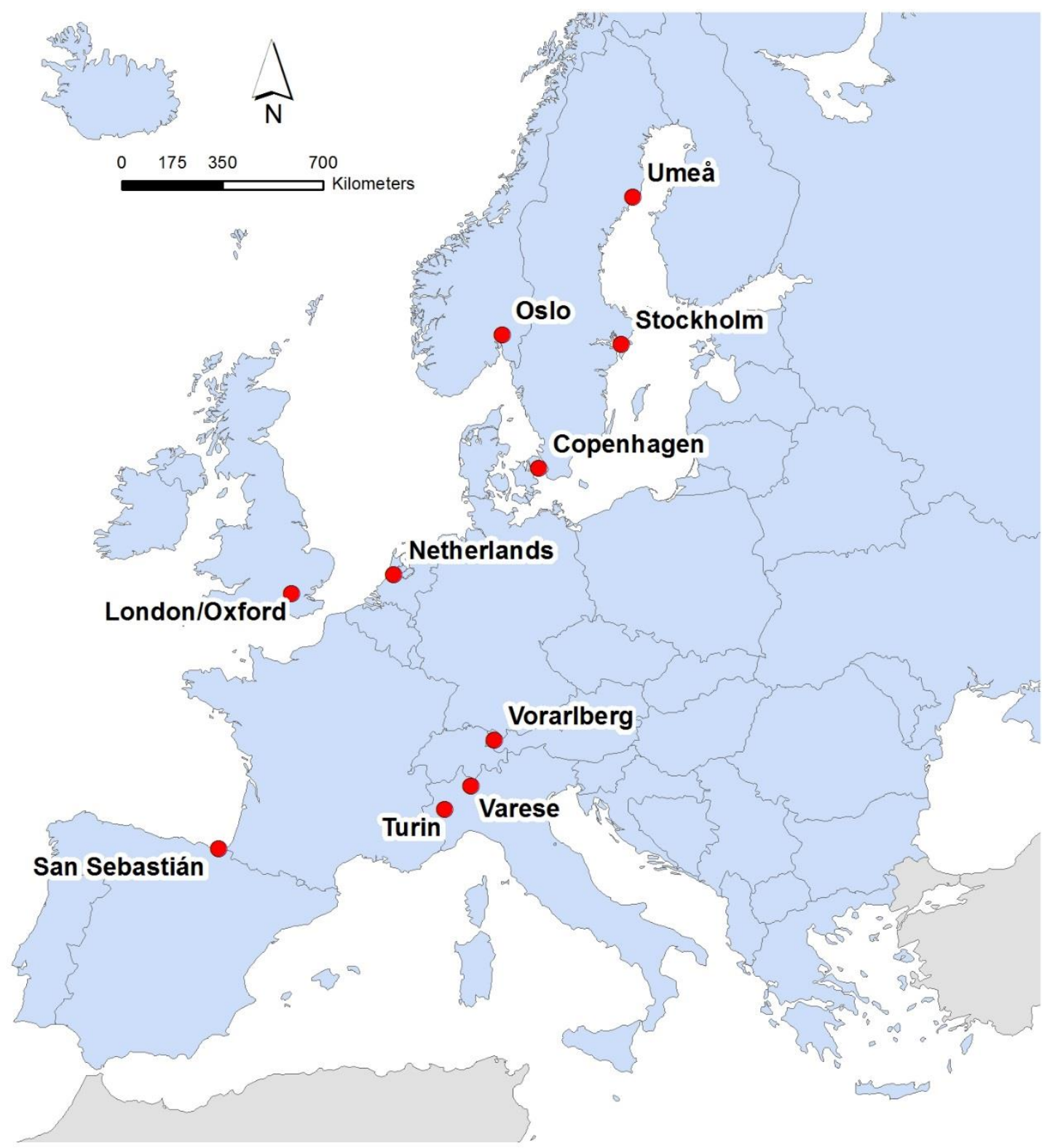


Figure 2. Cohort-specific associations between PM $_{2.5}$ (upper Forest plot, HRs per $5 \mu \mathrm{g} / \mathrm{m}^{3}$ ), $\mathrm{NO}_{2}$ (lower Forest plot, HRs per $10 \mu \mathrm{g} / \mathrm{m}^{3}$ ) and risk for kidney parenchyma cancer

Study

ID

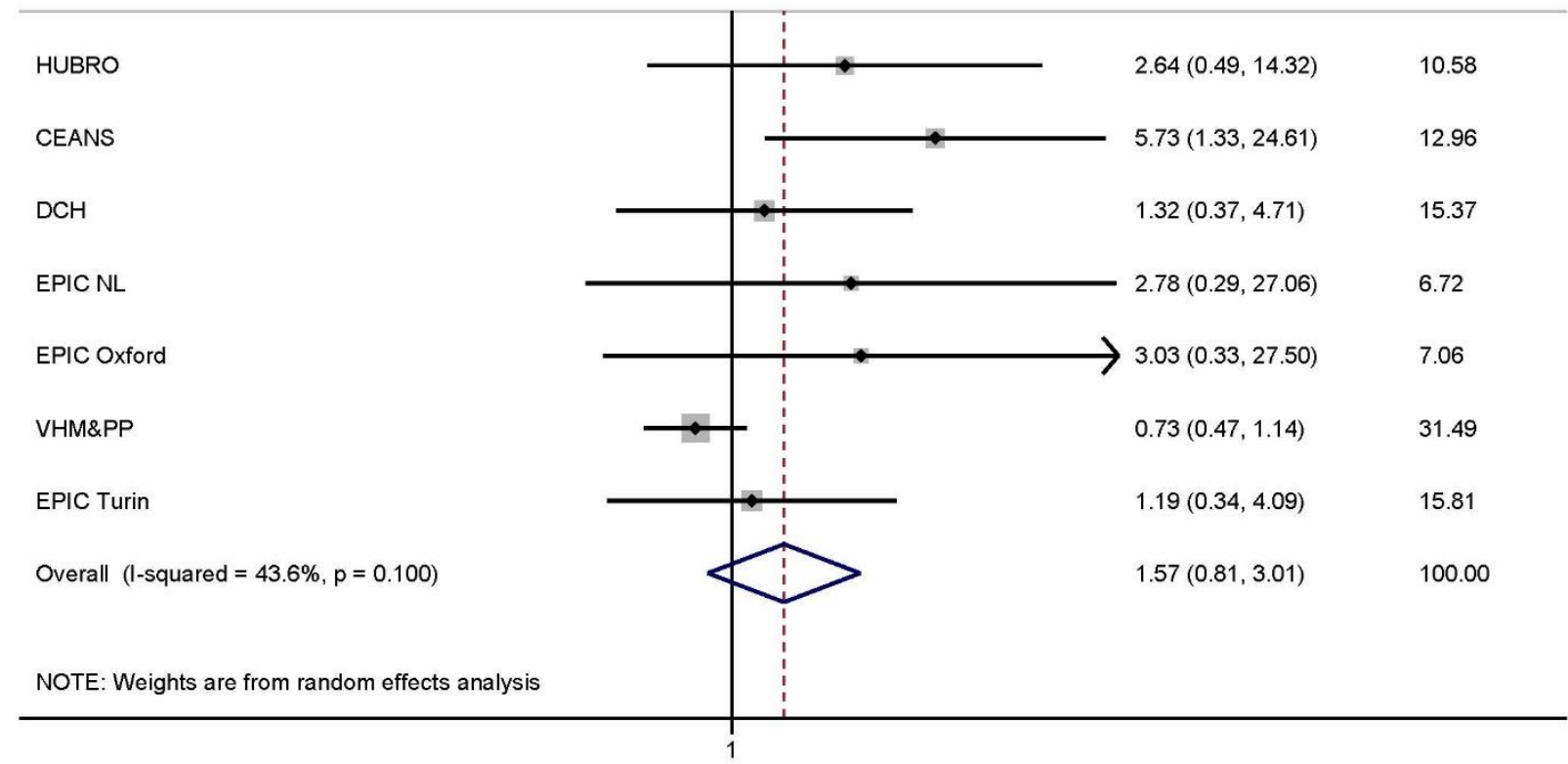

Study

$\begin{array}{ll}0.40(0.05,3.15) & 0.39 \\ 1.74(1.01,3.01) & 5.18 \\ 1.33(0.57,3.11) & 2.22 \\ 1.00(0.75,1.34) & 15.71 \\ 1.28(0.79,2.08) & 6.42 \\ 1.12(0.60,2.06) & 4.15 \\ 0.88(0.72,1.08) & 26.95 \\ 0.96(0.77,1.18) & 25.04 \\ 1.23(0.82,1.86) & 8.73 \\ 1.41(0.82,2.43) & 5.20 \\ 1.04(0.92,1.19) & 100.00\end{array}$

$\mathrm{DCH}$

EPIC NL

EPIC Oxford

VHM\&PP

EPIC Varese

EPIC Turin

EPIC San Sebastian

Overall $(I-$ squared $=13.1 \%, p=0.322)$
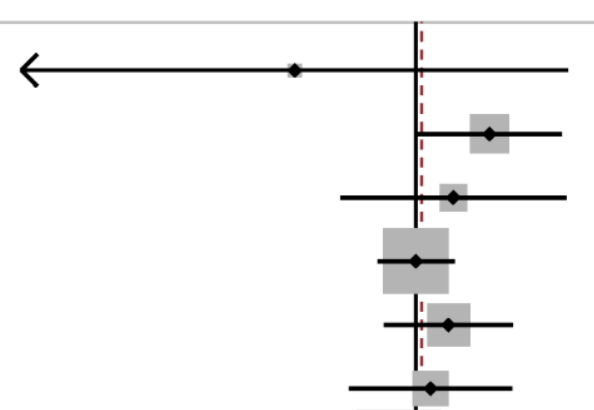

100.00
$\%$

Weight 